\title{
A Review of Domestic and International Research on New Media Marketing
}

\author{
Keran Wang ${ }^{1, \dagger}$ Ke Yang ${ }^{2,}{ }^{*}, \dagger$ Yushan Zheng ${ }^{3, \dagger}$ \\ ${ }^{1}$ Western University, N6A 3K7, London, Ontario, Canada \\ ${ }^{2}$ Henry W. Bloch School of Management, University of Missouri-Kansas City, 64110, Kansas City, Missouri, United \\ States \\ ${ }^{3}$ Newcastle University London, E1 7EZ, London, England \\ *Corresponding author. Email: kyf49@umsystem.edu \\ These authors contributed equally.
}

\begin{abstract}
With the development of science and technology and the popularity of the Internet and various smart devices, new media is growing rapidly worldwide, which has led to the development of new media marketing as a new international trend. Since there are numerous and wide range of studies in this field in China and abroad, this review aims to provide a clear overview of the research in the field of new media marketing. By using literary analysis and comparative research methods, the article mainly focuses on four dimensions of previous new media marketing studies, including concepts, manifestations, features, issues and solutions. Currently, domestic and foreign scholars have relatively consistent views on marketing features, but they have different opinions for the other three dimensions. Due to the late start of new media marketing in China, although the current studies have been gradually developed and improved, there is still a certain gap with foreign studies.
\end{abstract}

Keywords: New media, Marketing, Social media, Internet.

\section{INTRODUCTION}

New media is a form of dissemination that uses digital technology to provide users with information and services through computer networks, satellites, other channels, and computers, mobile phones, and other terminals. [1] New media currently mainly network new media, mobile new media, digital new media, etc., with six characteristics: data, interactivity, hypertext, virtuality, networking, and simulation. In the past 10 years, with the popularization of $4 \mathrm{G}$ networks and mobile terminals such as smartphones and tablet computers, especially after the official release of the WeChat public platform in 2012, the development of self-media and new media has been extremely rapid.

In view of the current development trend of network integration and media integration, from a broad network level, new media can also be called network media, and its development trend can be summarized as social networking and network socialization. From a micro point of view, why does academia pay attention to marketing? This is mainly due to the values formed in the new media environment. New media has changed people's understanding of the cognitive system, changed the way people construct value consciousness, changed the content of people's value consciousness construction, and changed the intensity of people's value consciousness construction. New media marketing is mainly embodied in four aspects: the technical level, the channel level, the terminal level, and the service level.

New media marketing [2] is popular with the public because of the proliferation of content production and the return of value appeals. The consumption power of new media users has upgraded, and the fragmentation of mobile consumption time has become more thorough and common. Users are obtaining more personalized and video-based information from more platforms and social chains, highlighting the value of content in the communication chain. Professional media organizations and self-media have made efforts in the content field to expand the boundaries of content production. Major platforms focus on the competition for high-quality content, the entrepreneurial climax of the content industry, and the Internet [3] content industry is surging. 
Although the domestic new media industry is in a period of rapid development, it is still out of sync with foreign new media marketing research, and a consensus has not yet been reached. The development of new media marketing is becoming an international trend [4], but how to develop and systematically study the background of new media at the macro and micro levels requires us to conduct an in-depth study of new media marketing. To understand and grasp, it is necessary to systematically study the background of new media at the macro and micro level, and then conduct further practice and research, and then achieve the high development of new media marketing in our country [5].

According to the background and phenomenon mentioned above, this article explores existing research on new media marketing in China and abroad. What is the current state of new media marketing in China and abroad? To what extend have Chinese and overseas scholars progressed in their new media research? To be more specific, what are the concepts, dominant manifestations, features, issues that have arisen, solutions proposed to address those issues in the study of new media marketing? What are the resemblances and distinctions in research between China and foreign countries in terms of those dimensions? What can we do to inform and help academia in the study field of new media marketing? Through comparing domestic and international studies? These are the main questions that we worked on in this paper.

Based on these research questions, by making use of literary analysis and comparative research method, we firstly visualized and analyzed the current situation of new media marketing research in China and foreign nations, and secondly compared and contrasted the domestic and foreign research, and eventually give a review, which allows us to sort out an evident lineage of research from numerous and wide-ranging pieces of literature, supporting people to understand the current situation of new media marketing in terms of Chinese and overseas studies and provide help and information for future researchers.

\section{VISUALIZATION ANALYSIS OF NEW MEDIA MARKETING LITERATURES}

This paper will analyze and review the domestic and international literature on the topic of new media marketing, respectively. China National Knowledge Infrastructure (CNKI) is the database used to search the domestic new media marketing literature. The keywords used in the retrieval of relevant literature are "new media" and "marketing". The retrieval time range is from 2010 to 2021. Google Scholar and Web of Science are the databases used to search the foreign new media marketing literature. The keywords used in the retrieval of relevant literature are "new media", "social media", "digital media", and "marketing". The retrieval time range is from 2010 to 2021. This paper will further analyze new media marketing at home and abroad in three aspects of research scale, research perspectives, and research quality.

\subsection{Research Scale}

The new media industry has developed rapidly worldwide in the last decade, and new media marketing is playing an important role in all fields. Even though the time spent on researching new media marketing is relatively short, its research scale is increasing year by year. From 2010 to 2021, the number of domestic literatures on new media marketing has increased to 1780. Meanwhile, the number of foreign literatures on new media marketing has increased to a big number. It shows that there is more and more academic research on new media marketing at home and abroad. Today, new media marketing has become a relatively new research area with essential research significance.

\subsection{Research Perspectives}

Using the keywords "new media" and "marketing" in the retrieval of domestic literature, there are several research perspectives on new media marketing. According to the statistics, it is mainly studied from four perspectives: economics and management, information technology, social science, and humanities. By using the keywords "new media", "social media", "digital media", and "marketing" in the retrieval of foreign literature, there are further research perspectives on new media marketing, such as commercial science, economics and management, information technology, media and communication, social science, and behavioral science. By comparison, foreign research perspectives on this topic are much broader due to the longer research time and larger research scale. In general, the rich research perspectives on the topic of new media marketing shows that this topic is currently important and popular.

\subsection{Research Quality}

Between 2010 and 2021, most of the domestic literatures on new media marketing are academic dissertations. Relatively speaking, there are not many high-quality scholarly journal papers and academic conference papers. At the same period, after counting the ratio of the number of literatures on new media marketing from Web of Science, which is a literature search website with higher quality, to the literature quantity from Google Scholar, there are not many highquality papers in the field of new media marketing in foreign countries, but there are more than domestic ones. To sum up, today, there is less high-quality research on this new field of new media marketing than 
other mature fields, and its influence has yet to be improved.

\section{RESEARCH PROGRESS OF NEW MEDIA MARKETING IN CHINA AND ABROAD}

\subsection{Review Domestic and Foreign Concept of New Media Marketing}

\subsubsection{Review Domestic Concept of New Media Marketing}

Goldmark, the director of the CBS Institute of Technology, the new media concept was first proposed in 1967 [6]. Since then, opinions on it have been divergent. For the research in China, scholar Wang Anyu believes that the new form of media that provides information to the audience through terminals such as mobile media and digital media is the new media [7]. Gong Chengbo summarized emerging media groups as online, mobile, interactive TV, outdoor, and new media groups [8]. Kuang Wenbo believes that the current new media can be roughly divided into three categories: network media, mobile media, and smart TV [9]. Jiang Hong and $\mathrm{Xu}$ Jian believe that new media include fiber optic cable communication networks, cable television networks, the Internet, mobile phone text messages, interactive platforms for multimedia information, and multimedia technology broadcast networks [10]. The definition of the concept of "new media" in China is through a variety of methods such as the definition of network technology, the definition of information form, and the comprehensive definition, and finally, a relatively reliable, clear, and effective conclusion is reached, which reflects the spread of new media. Academic characteristics.

\subsubsection{Review Foreign Concept of New Media Marketing}

The development of Internet technology abroad is relatively early, and the research on new media has a long history. It has distinct personality characteristics and pays attention to the individuality and interaction of people. For example, the German scholar Nicholas compared new media with old media in theoretical research. He also believes that new media is a form of person-to-person information dissemination; American "Wired" magazine explains that new media disseminates everyone to everyone. The cultural influence of humanism influences the research and definition of concepts and that all people are born equal. For example, Spanish scholar Sparter regards new media as a form parallel to mass and interpersonal media, and its basic feature is personalized information. Effective dissemination of data and equal control of data and information by different participants [11].

\subsubsection{Compare and Contrast Domestic and Foreign Concept of New Media Marketing}

There is mature research on the concept of "new media" abroad. Organizations such as UNESCO, Internet Lab, author of "Online" magazine, columnist of "San Jose Mercury" Dan Gilmore, Severin and many others are different. The new exploration of new media proposed during the period shows the profoundness of foreign research [12]. In addition, foreign countries have distinct personality characteristics for the study of its concept. The study and definition of the concept are influenced by humanism and focuses on the social relationship between people. On the contrary, in China, the starting point for its research was late, and early resources were scarce. In recent years, the Internet has exploded information, and the conceptual research of new media has gradually attracted attention and strengthened. Moreover, domestic research on the concept of "new media" is based on the study of traditional media. It is a new media concept based on the analysis and comparison of traditional media and the inheritance and development of old media.

\subsection{Review Domestic and Foreign New Media Marketing Strategies}

\subsubsection{Review Domestic New Media Marketing Strategies}

With the rapid development of the new media industry in the last decade, new media marketing has greatly impacted almost all kinds of enterprises. The research duration of new media marketing is relatively short, but its research scale increases year by year. Meanwhile, marketing strategy is one dimension that will definitely be studied while studying new media marketing. Therefore, the research and analysis of new media marketing strategies are also increasing. Especially nowadays, the domestic research on the dimension of new media marketing strategy has gradually become more abundant. According to four domestic pieces of literature on new media marketing, it is found that domestic scholars mainly analyse the new media marketing strategies from two categories, which are marketing model and marketing platform. On the one hand, domestic scholars analyse new media marketing strategies from the aspect of the marketing model. These scholars believe that due to the constant development of new media, markets or enterprises should continue to innovate the marketing models. In the era of new media, consumers focus on the product itself or services and pay more attention to experiential consumption. [13] Enterprises should build a marketing model which focuses on consumers' experiential 
consumption to satisfy their consumption needs in many ways [14]. They could use internet technology and start with online marketing channels to advance multimedia marketing, thereby improving the marketing effects and promoting more offline transactions [15]. On the other hand, domestic scholars analyse new media marketing strategies from another aspect of the marketing platform. These scholars believe that when enterprises implement specific marketing strategies, different forms of media should be introduced to enrich new media marketing platforms [16]. For instance, enterprises could actively develop web marketing platforms, mobile devices marketing platforms, mobile telephone marketing platforms, and so on [13]. In the era of new media, the development of multimedia marketing platforms will increase the scope and speed of integrated marketing communication, enhance the interaction between consumers and enterprises, and achieve the purpose of precision marketing [16].

\subsubsection{Review Foreign New Media Marketing Strategies}

The research time on the dimension of foreign new media marketing strategy is earlier and longer than domestic. Hence its research scale is also larger than domestic. Foreign scholars have studied a lot on new media marketing strategies, and their research mainly focuses on social media marketing or e-marketing. Today, foreign research on new media marketing strategies has become more abundant. Based on four foreign literatures on social media marketing, foreign scholars mainly analyze the social media marketing strategies from two aspects: establishing interactive relationships and differences from traditional marketing. First, foreign scholars believe that the interaction of social media could be a useful strategic tool and further converted into marketing capabilities [17, 20]. Effective marketing strategies on social media help build closer connections between consumers and enterprises or between consumers and consumers [18]. When establishing the interactive relationship with consumers at the personal level or facilitating experiential consumption, favorable affective responses will be triggered and converted into behavioral outcomes to achieve desired marketing results [19]. Second, foreign scholars mention that social media marketing strategies are different from traditional marketing strategies with special appeals [18]. Social media is real-time, and consumers could quickly obtain the latest information about products or services [17]. Effective social media marketing strategies could directly promote purchases or actions and produce word-of-mouth effects, such as making consumers willing to share these messages with others [18].

\subsubsection{Compare and Contrast Domestic and Foreign New Media Marketing Strategies}

In conclusion, domestic and foreign new media marketing research, domestic and foreign scholars believe that effective new media marketing strategies have become a part of successful corporate marketing, and there are various viewpoints worth studying. However, these scholars analyze new media marketing strategies from different focuses. Domestic scholars focus on general concepts, such as marketing models and marketing platforms. By contrast, foreign scholars emphasise specific viewpoints, which are the establishment of interactive relationships and differences between traditional marketing and social media marketing.

\subsection{Review Features of Domestic and Foreign New Media Marketing}

Owning to the fact that new media marketing was born with the development of the Internet and the popularity of smart devices, it involves the mindset of new media, which makes it have many new features that are different from marketing through traditional media.

\subsubsection{Review Features of Domestic New Media Marketing}

First, the considerable number of audiences and the wide range of spread of new media marketing is a crucial feature mentioned by several Chinese scholars because new media platforms are effortlessly accessible to all consumer groups. According to Sun Xiquan [13], with the popularity of the Internet, smartphones and smart TVs, the Internet and WeChat are widely used, making it possible for companies to have a broader mass base as implementing marketing activities using new media. Wang Junwen [21] and Zhao Feier [22] both agreed that new media guarantees marketing campaigns have a strong audience base and a wider message coverage. Moreover, it is customer-targeted for organizations who conduct marketing through new media, which is also a significant feature of new media marketing. As stated by Ma Zhiping [23], through analysing a large amount of data from social platforms, companies can effectively dig into users' needs and provide an evident market basis for product design and development by taking advantage of new media. Wang Lei and Wang Yong [24] further pointed out the importance of individualized notification for precise targeting of customer groups. Besides, the forms of new media marketing are diversified. On the one hand, Li Kan [25] declared that new media marketing promotes products or brands through diverse channels such as Weibo, WeChat, QQ. On the other hand, Liu Xiu [26] enumerated several forms of content to communicate, like pictures, text, animations, and videos, illustrating the diversity of new media marketing from another dimension. 


\subsubsection{Review Features of Foreign New Media Marketing}

Foreign scholars have also pointed out some characteristics of new media marketing, and their research on new media tends to focus on social media marketing and e-marketing. Nadaraja and Yazdanifard [27] said social media marketing has a wide variety of channels and forms. They also mentioned that the financial barrier for social media marketing is low, compared to traditional marketing methods that usually cost millions of dollars. It is simply capable of reaching their target consumers. Additionally, interactivity is also a frequently mentioned feature in foreign studies on new media marketing. Bajpai, Pandey and Shriwas [28] and Nadaraja and Yazdanifard [27] all introduced the interactivity of new media marketing, in which consumers are no longer just passive recipients but can actively interact with the companies. Furthermore, social media marketing has a large audience, described in an article by John Olotewo [29] as another feature of new media marketing because the number of registered and active users of different social media platforms is in billions. However, one coin has two sides. Just as Dr. Saravanakumar and Dr. SuganthaLakshmi [30] stated, social media marketing allows companies to communicate with their customers, market their products, even boost customer loyalty. However, it is still necessary to put effort into managing this communication because dissatisfied customers can speak aloud to negative the good brand's image.

\subsubsection{Compare and Contrast Domestic and Foreign New Media Marketing Features}

The understanding of new media marketing characteristics remains basically consistent in the studies of China and other countries. The great audience, wide channels, multiple forms, and strong interaction of new media marketing are common features pointed out by domestic and international studies. In addition, it is undeniable that the precise target audience of new media marketing is also a common key point in both domestic and foreign studies. It is worth noting that foreign studies on new media point out that the strong interaction with the audience may lead to a negative impact, which is seldom mentioned in domestic studies.

\subsection{Review Problems and Solutions of New Media Studies in China and Abroad}

\subsubsection{Review Problems and Solutions of New Media Marketing in China}

Chinese companies have a late start in developing new media marketing. In the new media marketing development process in China, scholars have raised some problems to be solved. First, Liu [26] and Long [31] both recognized that the lack of professional marketers is one of the problems new media marketing faces in China. They argue that marketing is a professional action, so professional marketing personnel with both marketing knowledge and new media usage skills needs to be developed. Secondly, scholars such as Liu Xiaosan [32] and Zheng Xin [33] also claimed that some companies are inclined to do marketing over their products when conducting new media marketing. Especially companies only focus on presenting fancy marketing tricks on new media while neglecting to guarantee the quality and value of the products themselves.

In response to these problems, Chinese scholars have proposed some solutions. Long [31] proposed that enterprises should strengthen the construction of new media marketing network systems and establish a highquality marketing team. Deng Shiwen [34] stated the quality of products should be strictly controlled to strengthen the protection of consumers' rights. Also Mentioned by Zheng [33], sellers should ensure the seamless integration of online and offline sales channels so that brands and products can be presented to consumers in a more three-dimensional way and new media marketing can play a real value.

\subsubsection{Review Problems and Solutions of New Media Marketing Overseas}

Although the development of new media marketing abroad varies from China, they also point out some problems. M. Sekar, R. Geetha [35] showed that privacy issues have not been fully addressed and concern most consumers. Nadaraja and Yazdanifard [27] also indicated that trademark and copyright issues are also the challenges faced by new media marketing, where third parties can misuse trademarks and copyrights.

Faced with those information and property security issues, many scholars suggested companies establish privacy policies to restrain themselves and others from misuse of information and regularly monitor the use of their trademarks and copyrights on media platforms.

\subsubsection{Compare and Contrast Problems and Solutions of New Media Marketing in China and Overseas}

In domestic and foreign studies of new media marketing, Chinese and foreign scholars have pointed out different problems. Chinese scholars have mainly 
focused on the problems faced in the marketing process and proposed feasible solutions. In contrast, overseas researchers have paid attention to the private security and trademark and copyright issues and the development of new media marketing.

Table 1. Summary of Domestic and Foreign Research of New Media Marketing

\begin{tabular}{|c|c|c|c|c|c|}
\hline & Concept & Marketing Strategy & Features & Problems & Solutions \\
\hline Domestic & $\begin{array}{l}\text { Reflect the spread of } \\
\text { new media academic } \\
\text { characteristics through } \\
\text { a variety of methods } \\
\text { (definition of network } \\
\text { technology, the } \\
\text { definition of } \\
\text { information form, or } \\
\text { comprehensive } \\
\text { definition) }\end{array}$ & $\begin{array}{l}\text { - Innovate the } \\
\text { marketing } \\
\text { models; } \\
\text { - Enrich new } \\
\text { media marketing } \\
\text { platforms }\end{array}$ & $\begin{array}{l}\text { - Interactivity; } \\
\text { - Large } \\
\text { Audience; } \\
\text { - Customer } \\
\text { Targeting; } \\
\text { - Wide Channels; } \\
\text { - Multiple } \\
\text { Content Forms }\end{array}$ & $\begin{array}{l}\text { - The Lack of } \\
\text { Professional } \\
\text { Marketers; } \\
\text { - Marketing } \\
\text { Over Products }\end{array}$ & $\begin{array}{l}\text { - } \text { Marketers } \\
\text { Selecting and } \\
\text { Training; } \\
\text { - Focus on } \\
\text { Product } \\
\text { Quality }\end{array}$ \\
\hline Foreign & $\begin{array}{l}\text { The study and } \\
\text { definition of the } \\
\text { concept are influenced } \\
\text { by humanism and } \\
\text { focuses on the social } \\
\text { relationship between } \\
\text { people. }\end{array}$ & $\begin{array}{l}\text { - Establishment of } \\
\text { interactive } \\
\text { relationships; } \\
\text { - Differences from } \\
\text { traditional } \\
\text { marketing }\end{array}$ & $\begin{array}{l}\text { - Interactivity; } \\
\text { - Large } \\
\text { Audience; } \\
\text { - Customer } \\
\text { Targeting; } \\
\text { - Wide Channels; } \\
\text { - Multiple } \\
\text { Content Forms }\end{array}$ & $\begin{array}{l}\text { - Privacy } \\
\text { Issues; } \\
\text { - Trademark \& } \\
\text { Copyright } \\
\text { Issues }\end{array}$ & $\begin{array}{l}\text { - Privacy } \\
\text { Policies; } \\
\text { - Regular } \\
\text { Monitor }\end{array}$ \\
\hline
\end{tabular}

\section{CONCLUSION}

\subsection{Problems and Solutions of New Media Studies in China and Abroad}

From Table 1, it is apparent that this review analysis on domestic and foreign new media marketing is divided into four dimensions: concepts, marketing strategies, marketing features, problems and solutions. By comparison, domestic and foreign scholars have the same viewpoints on new media marketing features. New media marketing is characterized by strong interaction, a large audience, wide channels, and multiple content forms in both domestic and foreign studies. Besides, the precise customer targeting of new media marketing is also the common focus of both domestic and foreign research.

However, there are certain differences in the other three dimensions. Foreign research on its concept content has distinct personality characteristics. The research and definition of the concept are influenced by humanism, focusing on the social relations of human beings. Foreign content research focuses on systematic, innovative thinking, multifaceted, multi-faceted research, rich, comprehensive, advanced content. On the contrary, in China, the research on new media started late, and resources were scarce in the early stage. In recent years, the Internet has caused the explosion of information, and the conceptual research on new media has gradually gained attention and strengthened. In addition, domestic research on the concept of "new media" is based on the study of traditional media. It is a new media concept formed by the analysis and comparison of traditional media, and it is the inheritance and development of old media. In terms of content, it is in the stage of reference, observation, and summary. Domestic and foreign scholars have researched different aspects from the research in new media marketing strategies and problems and solutions. These scholars analyze new media marketing strategies from different focuses (domestic focuses are marketing model and marketing platform, and foreign focuses are the establishment of interactive relationships and differences from traditional marketing). They pay attention to the problems faced by new media marketing and the relative solutions from different angles (domestic angles are marketing process, and foreign angles are privacy security and trademark and copyright issues).

From the research perspectives of these cited references, the research and analysis of new media marketing by both domestic and foreign scholars are commonly based on the perspectives of business and economy. Therefore, these scholars' research and their conclusions could summarize the development of some enterprises or companies in the marketing field during the new media era. However, there are differences between domestic and foreign research in new media 
marketing from research methods. Domestic scholars usually regard new media marketing as a macro concept to conduct a systematic analysis. The research in new media marketing is divided into analysing several common concepts under marketing to further research and conclude. By contrast, foreign scholars usually use qualitative research methods to study new media marketing in a specific industry or enterprise. They usually use primary data, such as using questionnaire surveys, interviews, to collect data and then summarize, compare, and conclude.

The establishment of ARPANET in the United States in 1969 marked the birth of the Internet. Due to the early emergence of new media in foreign countries, the research on new things was in full swing, with early development and high emphasis. Its development path was relatively mature. However, in 1994, when China was fully connected to the Internet and accompanied by the rapid development of new media in China, the research in related fields started from observation to comprehensive exploration and then to theoretical construction. In 1997, the People's Daily Online was officially launched, sponsored by the People's Daily. Since then, news websites have appeared one after another, which immediately triggered a research boom. In the 21st century, research on new media has gradually arisen. Until 2005, China's research was still in the initial observation, description, sorting, and thinking stage. After all-around promotion, the current research has been gradually developed and improved, but there is still a certain gap with foreign research.

\subsection{Shortcomings of New Media Marketing}

\subsubsection{Lack of attention by the Company}

First of all, many companies do not pay attention to new media marketing, do not realize the advantages of new media marketing, do not set up a special management department for work, new media marketing positions randomly assigned to other departments, unable to give full play to the advantages of the position. This also affects the profits of the company that the business value that enterprises obtain from it is impossible to estimate. Through new media marketing, the brand awareness of enterprises can be expanded so that more consumers can understand and stimulate their purchases, and customer stickiness can be improved. Ccustomer and profit in new media marketing are linked together, new media is the "line" among them. For enterprises that do not pay attention to new media marketing, long-term value will be lost.

\subsubsection{Lack of Talents}

At the same time, new media marketing team has problems such as insufficient ideological understanding, unscientific organizational structure, and unbalanced talent structure. The company's lack of attention has also affected the introduction of talents. Related personnel lack professional knowledge and practical ability and cannot fully play the advantages of new media marketing. There are not enough positions for the relevant talents to play.

\subsection{Research and Prospect}

There are points out that compared with traditional media, the advantages of new media are more attractive to enterprises. Many researchers also believe that enterprises should learn how to change their marketing thinking in the era of "Internet + " and mobile Internet. Due to the continuous development of the Internet, more and more consumers are affected by new media marketing. By combining the advantages of traditional marketing and new media marketing, enterprises can improve their control over consumers and market trends.

\subsubsection{Strengthen Attention and Improve the Theory}

Changes in consumer behavior require companies to rethink their marketing strategies in new media, and many companies face internal and external pressure to adopt a digital presence on social media platforms. The company should increase the importance of the new media marketing, improve marketing internally and external. When to conduct thorough research to the new media marketing can be based on the theory of relevant disciplines, such as consumer psychology, the deep analysis of existing problems and development trend of new media marketing, according to the different situation of the company, Marketing using different disciplines.

\section{REFERENCES}

[1] The Book Compilation Group, Training Materials for Civil Service Core Competency Enhancement, Beijing China Yanshi Publishing House, 2014.01.

[2] J. Hu, Current Situation and Prospect of New Media Marketing in the Mobile Internet Era, Journal of New media research, 2017, 3(23), pp. 36-38.

[3] Y. Li, New Media Marketing Strategy. Transformation Method based on "Internet + " era in: Journal of Tax, 2018 (4), pp. 223.

[4] Y. M. Wang, New Media Marketing under the Internet thinking .in: Journal of Chinese and Foreign Entrepreneurs, 2017(33), pp. 14-15.

[5] B. Wen, Analysis and Research on New media Marketing Methods under the Internet Thinking, 
Journal of Modern Economic Information, 2018(02), pp. 341

[6] Y. Qiu, Y. Liu, Introduction to New Media Marketing, Magazine of People's Posts and Telecommunications Press: Internet + New Media Marketing Planning Series, 2017(01), pp. 165.

[7] W. Y. An, Research on the Classification and Definition of New Media in the Communication Mode, Journal of News Communication, 2021(14), pp. 36-37.

[8] W. W. Ai, A Review of New Media Marketing Research in the Tourism Industry, Journal of Tourism Overview (the second half of the month), 2017(10), pp. 204-205.

[9] W. B. Kuang, The New Form of WeChat New Media, Journal of Group Speech, 2014 (2), pp. 22.

[10] H. Jiang, J. Xu, Introduction to New Media. In, Magazine of Shanghai Jiao Tong University Press, 2006.

[11] M. Zhang, Research on New Media Concept. Analysis, Journal of Anhui Science and Technology, 2016(09), pp. 31-32.

[12] H. Jiang. R. F. Lu, Interpretation of "New media", Journal of Journalism and Communication Research, 2011(2), pp. 35.

[13] X. Q. Sun, Analysis of Enterprise Marketing Strategy in New Media Environment, in: Market Modernization, 2017(06), pp. 78-79. DOI: 10.14013/j.cnki.scxdh.2017.06.044

[14] D. F. Wang, S. J. Huang, Enterprises' Marketing Strategy in the New Media Environment, in: Management and Administration, 2018(02), pp. 136-138. DOI: $\quad 10.16517 /$ j.cnki.cn121034/f.2018.02.040

[15] Y. Zhang, New Media Marketing Strategy and Management Innovation Experience, in: Journal of News Research, 2015,6(05), pp. 146-147.

[16] Z. H. Lu, Strategic Analysis of Marketing by Using New Media, in: Modern Business, 2013(27), pp. 69. DOI: 10.14097/j.cnki.5392/2013.27.090

[17] F. F. Li, J. Larimo, L. C. Leonidou, Social media marketing strategy: definition, conceptualization, taxonomy, validation, and future agenda, in: Journal of the Academy of Marketing Science, 2021(49), pp. 51-70. https://doi.org/10.1007/s11747-020-00733-3

[18] A. Wibowo, S.-C. Chen, U. Wiangin, Y. Ma, A. Ruangkanjanases, Customer Behavior as an Outcome of Social Media Marketing: The Role of Social Media Marketing Activity and Customer
Experience, Sustainability, 2021(13), pp. 189. https:// dx.doi.org/10.3390/su13010189

[19] W. Tafesse, A. Wien, Implementing Social Media Marketing Strategically: An Empirical Assessment, Journal of Marketing Management, 2018, DOI: 10.1080/0267257X.2018.1482365

[20] A. S. Ananda, Á. H. Garcíaa, L. Lambertib, NREL: A Comprehensive Framework of Social Media Marketing Strategic Actions for Marketing organizations, Journal of Innovation \& Knowledge, 2016, pp. 170-180. http://dx.doi.org/10.1016/j.jik.2016.01.003

[21] J. Wang, Corporate Marketing Strategies in the New Media Era, Marketing Management Review, 2016(02), pp. 50-51.

[22] F. Zhao, Studies on Marketing Strategy Under New Media Technology, China Market, 2020(09), pp. 132+170. DOI: 10.13939/j.cnki.zgsc.2020.09.132

[23] Z. Ma, New Media Marketing Strategy Research, China Collective Economy, 2014(16), pp. 55-56.

[24] L. Wang, Y. Wang, Marketing Environment of New Media and Innovation of Marketing Strategy, Journalism Communication, 2018(16), pp. 50-51..

[25] K. Li, The Transformation Method of New Media Marketing Strategy Based on " Internet Accelerated Speed" Era, China Market, 2019(17), pp. 130-131. DOI: 10.13939/j.cnki.zgsc.2019.17.130

[26] X. Liu, Analysis of new media marketing value trends in China, Journal of Commercial Economics, 2020(13), pp. 63-66.

[27] R. Nadaraja, R.Yazdanifard, Social Media Marketing: Advantages and Disadvantages, Center of Southern New Hempshire University, 2013, pp. $1-10$.

[28] V. Bajpai, S. Pandey, S. Shriwas, Social Media Marketing: Strategies \& Its Impact, International Journal of Social Science \& Interdisciplinary Research, 1(7), pp. 214-223.

[29] J. Olotewo, Social Media Marketing In Emerging Marketing, International Journal Of Marketing Research, 2(2), pp. 10-19. DOI: 10.5455/IJOMR.2016254411

[30] M. Saravanakumar, T. SuganthaLakshmi, Social Media Marketing, Life Science Journal 2012, 9(4), pp. 4444-4451.

[31] H. Long, Discuss the Problems and Countermeasures of New Media Marketing of Chinese Enterprises, Technological Pioneers, 2013(22), pp. 212. 
[32] X, Liu, Exploration of New Media Marketing Under Internet Thinking, China Internet, 2014(05), pp. 40-43.

[33] X. Zheng, Exploration on the New Media Marketing Strategies Under the Internet Thinking Mode, Management \& Technology of SME, 2021(06), pp. 136-137.

[34] S. Deng, Exploring the New Media Marketing Strategy of Enterprises Based on the Internet Background, Enterprise Reform and Management, 2021(11), pp. 107-108. DOI: 10.13768/j.cnki.cn113793/f.2021.1211

[35] M. Sekar, R. Geetha, Challenges and Opportunities of E-marketing, International Journal of Scientific Research and Management, 2013, pp.157-162. 